\title{
Endotracheal Cuff Pressures Generated by Different Members of the Anaesthesia Services in a Ghanaian Teaching Hospital
}

\author{
Akwasi Antwi-Kusi, Gabriel Boakye, Wilfred Sam Awortwi \\ Department of Anaesthesia and Intensive Care, Komfo Anokye Teaching Hospital, Kumasi, Ghana. \\ Email: antwikusi@yahoo.com \\ Received August $1^{\text {st }}, 2013$; revised September $2^{\text {nd }}, 2013$; accepted October $2^{\text {nd }}, 2013$ \\ Copyright (C) 2013 Akwasi Antwi-Kusi et al. This is an open access article distributed under the Creative Commons Attribution Li- \\ cense, which permits unrestricted use, distribution, and reproduction in any medium, provided the original work is properly cited.
}

\begin{abstract}
Background: The main function of the endotracheal tube (ETT) cuff is to ensure a tight seal between the tracheal wall and the endotracheal tube to prevent stomach contents from entering the trachea during ventilation thus preventing aspiration. Whereas excessive inflation of the cuff is associated with complications as a result of impaired blood supply to the trachea mucosa, low inflation pressure puts the patient at risk of aspiration. This study sought to find the accuracy of correctly estimating the cuff pressure and whether experience has effect on the accuracy. Methods: After approval from the Ethics Committee, we observed 199 patients who had general anaesthesia and had been intubated at the Komfo Anokye Teaching Hospital, Kumasi Ghana. Anaesthesia practitioners were blinded to the study. The endotracheal cuff pressure was measured using a low pressure manometer. The experience of the Anaesthetist was also noted. Results: Only $26 \%$ of the cuff pressures measured were within the acceptable range of $20-30 \mathrm{~cm} \mathrm{H}_{2} \mathrm{O} .4 .5 \%$ of the pressures measured were below the acceptable minimum value of $20 \mathrm{~cm} \mathrm{H}_{2} \mathrm{O}$ hence exposing the patient to the risk of aspiration. $68 \%$ of the cuff pressures measured were above the maximum pressure of $30 \mathrm{~cm} \mathrm{H}_{2} \mathrm{O}$. Physician anaesthetists were likely to inflate the cuff correctly. They had average inflation pressures of $24 \mathrm{~cm} \mathrm{H}_{2} \mathrm{O}$ with minimum and maximum inflation pressures of $15 \mathrm{~cm} \mathrm{H}_{2} \mathrm{O}$ and $32 \mathrm{~cm} \mathrm{H}_{2} \mathrm{O}$ respectively. Resident physician anaesthetists inflate the endotracheal pressures moderately high, an average of $41.64 \mathrm{~cm} \mathrm{H}_{2} \mathrm{O}$. Nurse anaesthetists and student nurse anaesthetists had a tendency to overinflate the endotracheal cuff above the recommended range of $20-30 \mathrm{~cm} \mathrm{H}_{2} \mathrm{O}$. Their mean inflating pressures were 64.7 and 68.54 respectively. Conclusion: ETT cuff pressures measured by the low pressure aneroid manometer in patients undergoing general anaesthesia in Komfo Anokye Teaching Hospital are routinely high and are significantly higher when inflated by nurse anaesthetists, student nurse anaesthetists and Anaesthesia residents.
\end{abstract}

Keywords: Endotracheal Cuff Pressure; Aneroid Manometer; Intubation; Tracheal Stenosis

\section{Introduction}

Endotracheal intubation is usually done by anaesthesiologists to secure the airway and deliver anaesthetic gases. Critical care doctors and emergency physicians also intubate patients with respiratory failure or patients at risk of aspiration [1,2]. The main function of the ETT cuff is to ensure that the cuff seals off the space between the tracheal wall and the endotracheal tube $[4,5]$. Underinflation of the ETT cuff will cause aspiration with its associated ventilator-associated pneumonia [6]. Over inflation of the cuff can compromise the blood supply to the trachea mucosa leading to ischaemia, necrosis, and possible tracheal stenosis $[7,8]$. The incidence of tracheal stenosis in adults has increased with the use of assisted ventilation. A lot of patients experience sore throat after endotracheal intubation. This sore throat following intubation may be a result of ischaemia of the tracheal and oropharyngeal mucosa [9-11]. Other serious complications of overinflation of the cuff are tracheal rupture and stenosis, tracheal necrosis, trachea-oesophageal fistula and laryngeal nerve palsy [12-14,18,19].

Research done on animals has shown that if the endotracheal cuff is inflated to $20 \mathrm{~cm} \mathrm{H}_{2} \mathrm{O}$ it may reduce the blood flow to the tracheal mucosa at normal blood pressure. This reduction may be dangerously low during the periods of severe hypotension [11]. A review of the literature on the ideal cuff pressure suggests that a cuff 
pressure between $20-30 \mathrm{~cm} \mathrm{H}_{2} \mathrm{O}$ be maintained to avoid complications $[15,16]$. The most objective way of measuring the endotracheal cuff pressure is by the use of the low pressure aneroid manometer $[18,20]$. Because of the unavailability of this equipment in many hospitals, the accuracy of the ETT cuff pressure is determined by palpating the pilot balloon [21]. Others inflate the cuff gradually till such a point where there is no audible leak around the tube. The aim of this study was to find out whether the endotracheal cuff pressure as determined by the palpation method at the Komfo Anokye Teaching Hospital by different members of the anaesthesia service was within the normal range of $20-30 \mathrm{~cm} \mathrm{H}_{2} \mathrm{O}$ and whether the experience of the provider inflating the cuff has any effect on the accuracy of the cuff pressure.

\section{Methods}

After approval from the Ethics and research committee of the Kwame Nkrumah University of Science and Technology/Komfo Anokye Teaching Hospital, 199 patients scheduled for surgeries for which endotracheal intubation was indicated were selected for the study. All patients were made to sign a consent form before they were included. Patients were excluded if the positioning for the surgery was prone. Again if the patient needed an ETT that was different from the normal being used e.g. Armoured ETT, he or she was excluded. The anaesthesia provider or his assistant doing the case was not briefed about the aims of the study. We felt if they knew the essence of measuring the cuff pressure it may influence our results. Those who asked were told what the low pressure aneroid manometer was used for since it was not known by many of the anaesthesia providers. All the ETT cuffs were inflated with air.

\subsection{Data Collection}

A research assistant was contracted and was taught how to use the low pressure aneroid manometer to measure the endotracheal cuff pressure. A computer generated random numbers were used to determine which theatre was to be used for the data collection at any particular time. A research assistant measured the endotracheal cuff pressure soon after intubation using the low pressure aneroid manometer (Rusche Germnay) (Figure 1).

Once the pressure was measured the assistant adjusted the pressure to normal range in order to avoid any complications. It is important to note that nitrous oxide was not used as part of the anaesthesia since nitrous oxide is known to increase endotracheal cuff pressure with time. The research assistant also recorded the size of the ETT, whether the surgery was elective or an emergency, and the rank of the personnel who inflated the cuff.

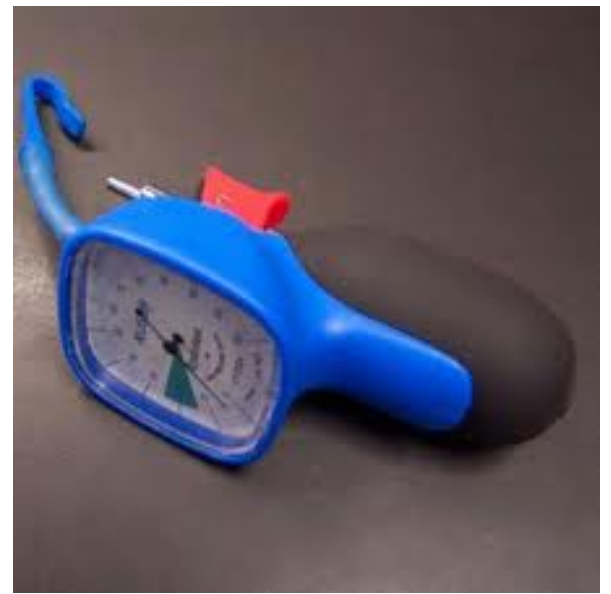

Figure 1. Low pressure aneroid manometer connected to the endotracheal tube.

\subsection{Statistical Analysis}

Data collected was entered using Microsoft soft excel 2007 and uploaded into SPSS version 16 for analysis. The P-value was 0.05 (i.e. $5 \%$ ) level of significance.

\section{Results (Figure 2 and Tables 1-3)}

The histogram shows that only seven out of the 199 measured cuff pressures was below the minimum recommended range of $20 \mathrm{~cm} \mathrm{H}_{2} \mathrm{O}$. Majority of the measured cuff pressures i.e. 138 were above the recommended upper limit of $30 \mathrm{~cm} \mathrm{H}_{2} \mathrm{O}$. It is of interest to note the frequency that was $120 \mathrm{~cm} \mathrm{H}_{2} \mathrm{O}$, the maximum limit of pressure that the manometer could measure. It is even likely that the pressure could have been beyond the 120 $\mathrm{cm} \mathrm{H}_{2} \mathrm{O}$ if the manometer could measure above $120 \mathrm{~cm}$ $\mathrm{H}_{2} \mathrm{O}$. Only 52 out of the 199 cuff pressures measured were within the recommended range. This is in line with the studies conducted by Parwani et al. showed that the cuff pressure is overestimated among Emergency physiccians, paramedic students and ICU staff when they use the palpation method to determine the cuff pressure.

The percentage of patients with ETT cuff pressure within and outside the recommended range of $20-30 \mathrm{~cm}$ $\mathrm{H}_{2} \mathrm{O}$ was $26.4 \%$ and $73.6 \%$ respectively. Thus, $73.6 \%$ of the measured pressures were outside i.e. either less or greater than the recommended range $\left(20-30 \mathrm{~cm} \mathrm{H}_{2} \mathrm{O}\right)$. $4.6 \%$ was below $20 \mathrm{~cm} \mathrm{H}_{2} \mathrm{O}$ and $69.0 \%$ was above $30 \mathrm{~cm}$ $\mathrm{H}_{2} \mathrm{O}$.

From Table 2 only 52 of the cuff pressures measured were within the recommended range. Specialist physician anaesthetists were more likely to correctly estimate the endotracheal cuff pressures. They had a probability of $87.5 \%$ being correct followed by Resident Anaesthetists who had a probability of $50 \%$ being correct. The category of anaesthesia providers with the least probability of 


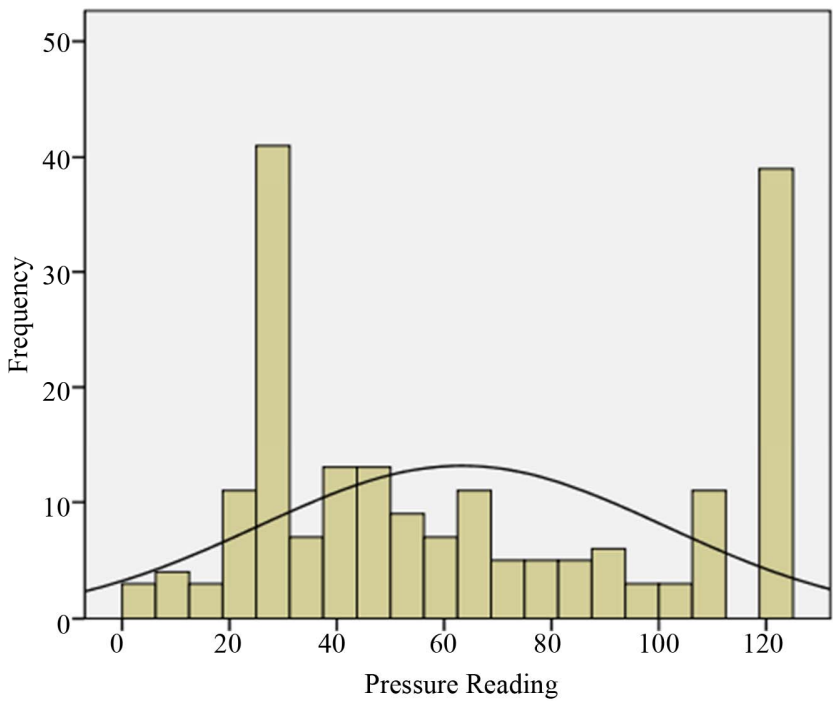

Mean $=63.28$

Std. Dev. $=37.805$

$\mathrm{N}=199$

Figure 2. Endotracheal cuff pressures as measured and their frequencies.

Table 1. ETT cuff pressure reading for various categories of anaesthesia providers.

\begin{tabular}{cc}
\hline Anaesthesia Providers & Mean \& Std Error \\
\hline Specialist Physician Anaesthetist & $24.00 \mathrm{~cm} \mathrm{H}_{2} \mathrm{O} \pm 1.94$ \\
Resident Physician Anaesthetist & $41.64 \mathrm{~cm} \mathrm{H}_{2} \mathrm{O} \pm 7.68$ \\
Nurse Anaesthetist & $64.67 \mathrm{~cm} \mathrm{H}_{2} \mathrm{O} \pm 3.98$ \\
Student Nurse Anaesthetist & $68.54 \pm 8.06$ \\
Others & $61.75 \pm 8.20$ \\
\hline
\end{tabular}

NB: Others included Health Care Assistants and non-anaesthesia staff in the theatre. The mean and standard deviation of the measured pressure is 63.28 $\pm 37.81$

Table 2. Category of pressure—within \& outside range.

\begin{tabular}{cccccc}
\hline & & Frequency & Percent & $\begin{array}{c}\text { Valid } \\
\text { Percent }\end{array}$ & $\begin{array}{c}\text { Cumulative } \\
\text { Percent }\end{array}$ \\
\hline \multirow{4}{*}{ Valid } & $\begin{array}{c}\text { Within } \\
\text { Range }\end{array}$ & 52 & 26.0 & 26.4 & 26.4 \\
& $\begin{array}{c}\text { Outside } \\
\text { Range }\end{array}$ & 145 & 72.5 & 73.6 & 100.0 \\
& Total & 197 & 98.5 & 100.0 & \\
Missing & Missing & 2 & 1.5 & & \\
\multicolumn{2}{c}{ Total } & 199 & 100.0 & & \\
\hline
\end{tabular}

estimating endotracheal cuff pressure correctly were student nurse anaesthetists who had a probability of $20 \%$. There was a significant difference of ETT cuff pressure readings and the level of training of the anaesthesia providers. Greater professional training resulted in safer
ETT cuff pressures. The Kruskal-Wallis test statistics suggest there is statistically significant difference among the professional groups with regard to pressure reading.

\section{Discussion}

The mean ETT cuff pressure was 63.28 with a standard deviation of $37.80 \mathrm{~cm}$ of $\mathrm{H}_{2} \mathrm{O}$. This is way beyond the recommended range of $20-30 \mathrm{~cm} \mathrm{H}_{2} \mathrm{O} .68 \%$ of the recorded pressures were above the recommended normal range. This proportion is higher than the work done by Bratz et al. where $45 \%$ of patients after anaesthesia without nitrous oxide had their endotracheal cuff pressure above the recommended range [5]. The endotracheal tubes used for the intubation were the large volume low pressure type. Because of their larger surface area, this type of tube does not exert so much pressure on the tracheal mucosa as compared to the high pressure low volume cuffs. However this large volume low pressure cuffs have the tendency to be overinflated thus transmitting such pressures that will exceed the perfusion pressures of the capillaries supplying blood flow to the trachea mucosa $[23,24]$. This may be the reason why a greater percentage of the cuff pressures were excessively high.

The percentage of patients with cuff pressure within and outside the recommended range $20-30 \mathrm{~cm} \mathrm{H}_{2} \mathrm{O}$ is $26.4 \%$ and $73.6 \%$ respectively. Thus, $73.6 \%$ of the measured pressures were outside i.e. either less or greater than the recommended range $\left(20-30 \mathrm{H}_{2} \mathrm{O}\right) .4 .6 \%$ was below $20 \mathrm{~cm} \mathrm{H}_{2} \mathrm{O}$ and $69.0 \%$ was above $30 \mathrm{~cm} . \mathrm{H}_{2} \mathrm{O}$

Only $4.6 \%$ of the measured endotracheal cuff pressures were below the normal recommended range. This 
Table 3. Professional category versus category of pressures-within \& outside range.

\begin{tabular}{|c|c|c|c|c|c|}
\hline \multicolumn{6}{|c|}{ Crosstab } \\
\hline & & & \multicolumn{2}{|c|}{$\begin{array}{c}\text { Category of Pressure-Within } \\
\text { \& Outside Range }\end{array}$} & \multirow{2}{*}{ Total } \\
\hline & & & Within Range & Outside Range & \\
\hline & & Count & 7 & 1 & 8 \\
\hline & $\begin{array}{c}\text { Specialist Physician } \\
\text { Anaesthetist }\end{array}$ & $\%$ within Professional Category & $87.5 \%$ & $12.5 \%$ & $100.0 \%$ \\
\hline & & $\%$ within Category of Pressure—Within \& Outside Range & $16.7 \%$ & $0.9 \%$ & $5.2 \%$ \\
\hline & & Count & 7 & 7 & 14 \\
\hline & $\begin{array}{l}\text { Resident Physician } \\
\text { Anaesthetist }\end{array}$ & $\%$ within Professional Category & $50.0 \%$ & $50.0 \%$ & $100.0 \%$ \\
\hline & & $\%$ within Category of Pressure-Within \& Outside Range & $16.7 \%$ & $6.3 \%$ & $9.2 \%$ \\
\hline & & Count & 17 & 66 & 83 \\
\hline \multirow[t]{11}{*}{$\begin{array}{l}\text { Professional } \\
\text { Category }\end{array}$} & Nurse Anaesthetist & $\%$ within Professional Category & $20.5 \%$ & $79.5 \%$ & $100.0 \%$ \\
\hline & & $\%$ within Category of Pressure-Within \& Outside Range & $40.5 \%$ & $59.5 \%$ & $54.2 \%$ \\
\hline & & Count & 10 & 35 & 45 \\
\hline & $\begin{array}{c}\text { Student Nurse } \\
\text { Anaesthetist }\end{array}$ & $\%$ within Professional Category & $20.0 \%$ & $80.0 \%$ & $100.0 \%$ \\
\hline & & $\%$ within Category of Pressure-Within \& Outside Range & $11.9 \%$ & $18.0 \%$ & $16.3 \%$ \\
\hline & & Count & 11 & 38 & 49 \\
\hline & Others & $\%$ within Professional Category & $26.1 \%$ & $73.9 \%$ & $100.0 \%$ \\
\hline & & $\%$ within Category of Pressure—Within \& Outside Range & $14.3 \%$ & $15.3 \%$ & $15.0 \%$ \\
\hline & & Count & 52 & 147 & 199 \\
\hline & Total & $\%$ within Professional Category & $27.5 \%$ & $72.5 \%$ & $100.0 \%$ \\
\hline & & $\%$ within Category of Pressure-Within \& Outside Range & $100.0 \%$ & $100.0 \%$ & $100.0 \%$ \\
\hline
\end{tabular}

does not compare with other studies done elsewhere. Bratz et al. reported $14.8 \%$ of cases below the recommended normal range [5]. Even though insufficient cuff pressures can lead to aspiration of infected oropharyngeal secretions when low, or induce tracheal lesions when high. This study showed that anaesthesia providers in Komfo Anokye Teaching Hospital tended to overinflate the ETT cuff balloon which would prevent aspiration. This in part could explain why only $4.6 \%$ of the ETT cuff pressures were below the minimum pressure range. The practice of overinflation of ETT cuff pressures shouldn't be encouraged since tracheal mucosal ischaemia and or stenosis could develop after prolonged periods of tracheal intubation [24].

There is significant difference between levels of profession and pressure reading. Greater professional training correlated with safer ETT cuff measurements in this study. This may be due to their level of education which involves the study of the pathophysiology of diseases. With this knowledge in mind, they are careful in inflating the cuff with excessive pressures which can damage the trachea.

The Kruskal-Wallis test statistics indicates that ETT cuff pressure reading is influenced by professional training. This is in line with the discussion made earlier (Table 3) that the greater the profession of the anaesthetist, the better the pressure reading. This test was necessitated since the data fails on normality.

It is disturbing the number of extremely high values of endotracheal cuff pressures measured by participants in this study. This is more than what is recorded in other studies [12].

Apart from the specialist physician anesthetists who were more likely to record ETT cuff pressures within the recommended range, all other categories of anaesthesia providers irrespective of their level of experience recorded 
values that were outside the normal recommended range. This is in line with other studies showing that the skill of estimating the accuracy of the ETT cuff pressure is not acquired by one's level of training or experience [25]. It is therefore encouraging to note that the physician Anaesthetists were more likely to correctly estimate the ETT cuff pressure. These Physician Anaesthetists had been trained in centers where the aneroid manometer was routinely used. This may explain why they were able to accurately estimate the ETT cuff pressure.

\section{Conclusion}

Endotracheal cuff pressures measured by the low pressure aneroid manometer are abnormally high in patients undergoing endotracheal intubation at the Komfo Anokye Teaching Hospital. Providers with greater training (anaesthesiologists) demonstrate safer ETT cuff pressures when compared to nurse anaesthetists, student nurse anaesthetists and anaesthesia residents.

\section{Recommendation}

ETT cuff pressure should be routinely measured using low pressure manometer to minimise trauma to the trachea (mucosa and surrounding structures) and prevent aspiration.

There should be a clear policy on how much ETT cuff inflation pressure and volume should be used to provide safe endotracheal intubation.

There should be a continuous professional development for all anaesthesia providers on endotracheal cuff pressure and its effect on the tracheal mucosa.

\section{REFERENCES}

[1] A. Aitkenhead, "Test Book of Anaesthesia," 5th Edition, Churchill Livingstone, London, 2007.

[2] P. Sengupta, D. I. Sessler, P. Maglinger, S. Wells, A. Vogt, J. Durrani, et al., "Endotracheal Tube Cuff Pressure in Three Hospitals, and the Volume Required to Produce an Appropriate Cuff Pressure," BMC Anesthesiology, Vol. 4, No. 1, 2004, p. 8.

[3] Chanmugam, "Clinical Procedures in Emergency Medicine," 4th Edition, Saunders, Philadelphia, 2004.

[4] R. Fernandez, L. Blanch, J. Mancebo, N. Bonsoms and A. Artigas, "Endotracheal Tube Cuff Pressure Assessment: Pitfalls of Finger Estimation and Need for Objective Measurement," Critical Care Medicine, Vol. 18, No. 12, 1990, pp. 1423-1426. http://dx.doi.org/10.1097/00003246-199012000-00023

[5] J. R. Braz, L. H. Navarro, I. H. Takata and P. Nascimento Jr., "Endotracheal Tube Cuff Pressure: Need for Precise Measurement," Sao Paulo Medical Journal, Vol. 117, No. 6, 1999, pp. 243-247. http://dx.doi.org/10.1590/S1516-31801999000600004
[6] L. Trivedi, P. Jha, N. R. Bajiya and D. Tripathi, "We Should Care More about Intracuff Pressure: The Actual Situation in Government Sector Teaching Hospital," Indian Journal of Anaesthesia, Vol. 54, No. 4, 2010, pp. 314-317. http://dx.doi.org/10.4103/0019-5049.68374

[7] R. D. Seegobin and G. L. van Hasselt, "Endotracheal Cuff Pressure and Tracheal Mucosal Blood Flow: Endoscopic Study of Effects of Four Large Volume Cuffs," British Medical Journal (Clinical Research Edition), Vol. 288, No. 6422, 1984, pp. 965-968. http://dx.doi.org/10.1136/bmj.288.6422.965

[8] M. J. Silva, J. Aparício, T. Mota, J. Spratley and A. Ribeiro, "Ischemic Subglottic Damage Following a ShortTime Intubation," European Journal of Emergency Medicine, Vol. 15, No. 6, 2008, pp. 351-353. http://dx.doi.org/10.1097/MEJ.0b013e3282fc9c5d

[9] J. A. Curiel García, F. Guerrero-Romero and M. Rodríguez-Morán, "Cuff Pressure in Endotracheal Intubation: Should It Be Routinely Measured?" Gaceta Médica de México, Vol. 137, No. 2, 2001, pp. 179-182.

[10] P. Pelc, T. Prigogine, P. Bisschop and A. Jortay, "Tracheoesophageal Fistula: Case Report and Review of Literature," Acta Otorhinolaryngologica Belgica, Vol. 55, No. 4, 2001, pp. 273-278.

[11] J. Stauffer, D. Olson and T. Petty, "Complications and Consequences of Tracheal Intubation and Tracheostomy," The American Journal of Medicine, Vol. 70, No. 1, 1981, pp. 65-76.

http://dx.doi.org/10.1016/0002-9343(81)90413-7

[12] V. Parwani, I. Hahn and R. Hoffmann, "Experienced Paramedics Cannot Inflate or Estimate Endotracheal Tube Cuff Pressure Using Standard Techniques," Annals of Emergency Medicine, Vol. 48, No. 4, 2006, pp. 20-24.

[13] A. Doyle, R. Santhirapala, M. Crowe, M. Blunt and P. Young, "The Pressure Exerted on the Tracheal Wall by Two Endotracheal Tube Cuffs: A Prospective Observational Bench-Top, Clinical and Radiological Study," BMC Anesthesiology, Vol. 10, 2010, p. 21. http://dx.doi.org/10.1186/1471-2253-10-21

[14] E. A. Loeser, D. L. Orr 2nd, G. M. Bennett and T. H. Stanley, "Endotracheal Tube Cuff Design and Postoperative Sore Throat," Anesthesiology, Vol. 45, No. 6, 1976, pp. 684-687. http://dx.doi.org/10.1097/00000542-197612000-00023

[15] A. Gottschalk, M. A. Burmeister, I. Blanc, F. Schulz and T. Standl, "Rupture of the Trachea after Emergency Endotracheal Intubation," Anasthesiol Intensivmed Notfallmed Schmerzther, Vol. 38, No. 1, 2003, pp. 59-61. http://dx.doi.org/10.1055/s-2003-36557

[16] V. Nesek-Adam, V. Mrsić, D. Oberhofer, E. GrizeljStojcić, D. Kosuta and Z. Rasić, "Post-Intubation LongSegment Tracheal Stenosis of the Posterior Wall: A Case Report and Review of the Literature," Journal of Anesthesia, Vol. 24, No. 4, 2010, pp. 621-625. http://dx.doi.org/10.1007/s00540-010-0956-8

[17] R. Wason, P. Gupta and A. R. Gogia, "Bilateral Adductor Vocal Cord Paresis Following Endotracheal Intubation for General Anaesthesia," Anaesth Intensive Care, Vol. 
32, No. 3, 2004, pp. 417-418.

[18] M. F. Reed and D. J. Mathisen, "Tracheoesophageal Fistula," Chest Surgery Clinics of North America, Vol. 13, No. 2, 2003, pp. 271-289. http://dx.doi.org/10.1016/S1052-3359(03)00030-9

[19] Y. Sanada, Y. Kojima and E. W. Fonkalsrud, "Injury of Cilia Induced by Tracheal Tube Cuffs," Surgery, Gynecology \& Obstetrics, Vol. 154, No. 5, 1982, pp. 648-652.

[20] J. R. Bouvier, "Measuring Tracheal Tube Cuff Pressures -Tool and Technique," Heart \& Lung, Vol. 10, No. 4, 1981, pp. 686-690.

[21] J. F. Berlauk, "Prolonged Endotracheal Intubation vs. Tracheostomy," Critical Care Medicine, Vol. 14, No. 8, 1986, pp. 742-745. http://dx.doi.org/10.1097/00003246-198608000-00017

[22] R. J. Hoffman, V. Parwani and I.-H. Hahn, "Experienced Emergency Medicine Physicians Cannot Safely Inflate or Estimate Endotracheal Tube Cuff Pressure Using Standard Techniques," American Journal of Emergency Medicine, Vol. 24, No. 2, 2006, pp. 139-143. http://dx.doi.org/10.1016/j.ajem.2005.07.016

[23] A. M. Black and R. D. Seegobin, "Pressures on Endotracheal Tube Cuffs," Anaesthesia, Vol. 36, No. 5, 1981, pp. 498-511. http://dx.doi.org/10.1111/j.1365-2044.1981.tb10286.x

[24] J. L. Stauffer, D. Olson and T. Petty, "Complications and Consequences of Tracheal Intubation and Tracheostomy: A Prospective Study of 150 Critically Adult Patients," The American Journal of Medicine, Vol. 70, No. 1, 1981, pp. 65-76. http://dx.doi.org/10.1016/0002-9343(81)90413-7

[25] V. Parwani, R. J. Hoffman, A. Russell, C. Bharel, C. Preblick and I.-H. Hahn, "Practicing Paramedics Cannot Generate or Estimate Safe Endotracheal Tube Cuff Pressure Using Standard Techniques," Prehospital Emergency Care, Vol. 11, No. 3, 2007, pp. 307-311. http://dx.doi.org/10.1080/10903120701348248 